Check for updates

Cite this: RSC Adv., 2021, 11, 30093

Received 6th July 2021

Accepted 25th August 2021

DOI: 10.1039/d1ra05201b

rsc.li/rsc-advances

\section{Fluorometric trace methanol detection in ethanol and isopropanol in a water medium for application in alcoholic beverages and hand sanitizers $\dagger$}

\begin{abstract}
Snigdha Roy, ${ }^{a}$ Sanju Das, ${ }^{b}$ Ambarish Ray ${ }^{\star c}$ and Partha Pratim Parui (iD *a
Detection of methanol $(\mathrm{MeOH})$ in an ethanol $(\mathrm{EtOH}) /$ isopropanol $\left({ }^{i} \mathrm{PrOH}\right)$ medium containing water is crucial to recognize $\mathrm{MeOH}$ poisoning in alcoholic beverages and hand sanitizers. Although chemical sensing methods are very sensitive and easy to perform, the chemical similarities between the alcohols make $\mathrm{MeOH}$ detection very challenging particularly in the presence of water. Herein, the fluorometric detection of a trace amount of $\mathrm{MeOH}$ in $\mathrm{EtOH} / \mathrm{PrOH}$ in the presence of water using alcohol coordinated $\mathrm{Al}(\mathrm{III})$-complexes of an aldehydic phenol ligand containing a dangling pyrazole unit is described. The presence of $\mathrm{MeOH}$ in the $\mathrm{EtOH} / \mathrm{PrOH}$ causes a change of the complex geometry from tetrahedral ( $\mathrm{Td}$ ) to octahedral $(\mathrm{Oh})$ due to the replacement of the coordinated $\mathrm{EtOH} /{ }^{i} \mathrm{PrOH}$ by $\mathrm{MeOH}$ molecules. The Td-complex exhibited fluorescence but the Oh-species did not, because of the intramolecular photo-induced electron transfer (PET). By interacting the Oh species with water, its one $\mathrm{MeOH}$ coordination is replaced by a water molecule followed by the proton transfer from the water to pyrazole- $\mathrm{N}$ which generates strong fluorescence by inhibiting the PET. In contrast, the water interaction dissociates the Td-complex to exhibit fluorescence quenching. The water induced reversal of the fluorescence response from the decrease to increase between the absence and presence of $\mathrm{MeOH}$ is utilized to detect $\mathrm{MeOH}$ in an $\mathrm{EtOH} /{ }^{\prime} \mathrm{PrOH}$ medium containing water with a sensitivity of $\sim 0.03-0.06 \%$ $(\mathrm{v} / \mathrm{v})$. The presence of water effected the $\mathrm{MeOH}$ detection and allows the estimation of the $\mathrm{MeOH}$ contamination in alcoholic beverages and hand sanitizers containing large amounts of water.
\end{abstract}

\section{Introduction}

Worldwide, hundreds of economically constrained people are dying every year because of consumption of methanol (MeOH) contaminated illicit liquors. ${ }^{\mathbf{1 - 3}}$ In the countryside, use of crude fermentation methods and improper distillation are the main culprits for the $\mathrm{MeOH}$ contamination in ethanol (EtOH). In some cases, unavoidable $\mathrm{MeOH}$ formation during standard fermentation processes is also a major concern. ${ }^{4}$ Consumption of $\mathrm{MeOH}$ beyond a certain permissible limit (1-2 $\mathrm{mL}$ per $\mathrm{kg}$ body mass) directly affects the central nervous system, by inhibiting the activity of cytochrome c oxidase, causing hypoxia, acidosis or even a painful death. ${ }^{5-9}$ Even a minute amount of $\mathrm{MeOH}$ ingestion, approximately $10 \mathrm{~mL}$ of dietary intake, is potent enough to cause some adverse effects. ${ }^{10,11}$ The use of much less expensive $\mathrm{MeOH}$ is a very common illegal practice aepartment of Chemistry, Jadavpur University, Kolkata 700032, India. E-mail:
parthaparui@yahoo.com; Fax: +91-33-24146223; Tel: $+91-9433490492$
${ }^{b}$ Department of Chemistry, Maulana Azad College, Kolkata 700013, India
${ }^{c}$ Department of Chemistry, Barasat Govt. College, Kolkata 700124, India. E-mail:
r_ambarish@yahoo.co.in; Tel: +91-9836650180

$\dagger$ Electronic supplementary information (ESI) available. See DOI: 10.1039/d1ra05201b used to alter the EtOH strength in alcoholic beverages to give a higher profit. Nevertheless, in recent times during the COVID19 pandemic, a large number of poisonous $\mathrm{MeOH}$ containing hand sanitizers were seized worldwide, even after repeated warnings from the FDA. ${ }^{12}$ Because the use of costly EtOH and isopropanol $\left({ }^{i} \mathrm{PrOH}\right)$ based hand sanitizers has significantly increased to help combat the COVID-19 pandemic, indiscriminate commercial production inevitably increases the chance of using $\mathrm{MeOH}$ containing cheaper hand sanitizers. ${ }^{\mathbf{1 2}}$

The $\mathrm{MeOH}$, EtOH and ${ }^{i} \mathrm{PrOH}$ are all chemically similar in nature. ${ }^{13-15}$ Thus, using a reaction based chemical sensor, $\mathrm{MeOH}$ detection in commercial alcoholic beverages and hand sanitizers containing a large amount of $\mathrm{EtOH} /{ }^{i} \mathrm{PrOH}$ as well as water is an extremely challenging task. ${ }^{16-18}$ In the search for an alternative method of detection, researchers focused on various other analytical procedures, such as different types of mass spectrometry (MS), ${ }^{19-21}$ gas chromatography, ${ }^{22-24}$ cyclic voltammetry, ${ }^{25}$ capillary electrophoresis, ${ }^{26}$ quartz crystal microbalances (QCMs) and so on. ${ }^{27}$ However, costly sophisticated instrumentation, the requirement of skilled technicians or tedious standardizations for the previous methods are major disadvantages for using them in routine analysis. In view of their cost-effectiveness and easy detection protocol, the reaction 
based chemical sensing methods are far superior detection techniques.

Fluorometric chemical sensing because of its ultra-high sensitivity is considered to be one of the most effective methods. Despite this, few organic fluorescent probes for $\mathrm{MeOH}$ are reported in the literature and those that are have certain limitations..$^{17,28-30}$ Different materials have also been used as $\mathrm{MeOH}$ fluorosensors such as a supramolecular ionic material by Zhang et al., ${ }^{31}$ a bimetallic lanthanide-organic framework by $\mathrm{Du}$ and co-workers, ${ }^{32}$ and nitrogen-doped oxidized carbon dots by Latha et $a l^{33}$ In most of the cases $\mathrm{MeOH}$ is differentiated only from EtOH but not from ${ }^{i} \mathrm{PrOH}$. The detection is based on either an increase or decrease of the relative intensity changes between $\mathrm{MeOH}$ and $\mathrm{EtOH}$ but never in the opposite direction, that is an increase for one and a decrease for the other. In addition, the effect of a large amount of water in the sample being analyzed for $\mathrm{MeOH}$, although useful in the preparation of alcoholic beverages and hand sanitizers, has not been thoroughly investigated. Thus, it is proposed that the $\mathrm{MeOH}$ detection based on water induced a reverse fluorescence response for the probe such as an increase in intensity in the presence of $\mathrm{MeOH}$ but a decrease in intensity in its absence for a $\mathrm{EtOH} /{ }^{i} \mathrm{PrOH}$ medium.

The aldehydic phenol ligand (PPY) and its alcohol coordinated $\mathrm{Al}(\mathrm{III})$-complexes were strategically synthesized, and they exhibited a water mediated $\mathrm{MeOH}$ selective fluorometric response. The presence of $\mathrm{MeOH}$ in $\mathrm{EtOH} /{ }^{i} \mathrm{PrOH}$ induces a change in the complex geometry from a fluorescent tetrahedral (Td) form to a weakly fluorescent octahedral (Oh) form, which is due to the exchange of coordinated $\mathrm{EtOH} /{ }^{i} \mathrm{PrOH}$ by $\mathrm{MeOH}$. The interaction of water with the Oh-species exhibited a strong fluorescence intensity because of the exchange of its one coordinated $\mathrm{MeOH}$ with a water molecule followed by an intramolecular proton transfer from the coordinated water to the ligand moiety. However, the less stable Td-complex in the absence of $\mathrm{MeOH}$ is dissociated by the water interaction to exhibit an intensity decrease. Such water induced opposite intensity changes between the absence and presence of $\mathrm{MeOH}$ are utilized to detect $\mathrm{MeOH}$ in $\mathrm{EtOH} /{ }^{i} \mathrm{PrOH}$ and in alcoholic beverages/hand sanitizers in a water medium.

\section{Experimental}

The general experimental procedures and materials are described on page S2 of the ESI. $\dagger$

\section{Synthesis of PPY}

Firstly, 3,5-dimethylpyrazole (1) and 2-hydroxy-3(hydroxymethyl)-5-methylbenzaldehyde (2) were synthesized according to published procedures. ${ }^{34,35}$ To synthesize 3(chloromethyl)-2-hydroxy-5-methylbenzaldehyde (3), 2 (0.5 mol) was taken in $2 \mathrm{~mL}$ of dichloromethane (DCM, $\mathrm{CH}_{2} \mathrm{Cl}_{2}$ ) and the suspension obtained was stirred. Freshly distilled $\mathrm{SOCl}_{2}$ in DCM was added drop wise (final ratio of $\mathrm{SOCl}_{2}: \mathrm{DCM}=1: 1$ ) under constant stirring. The yellow colored solution obtained was then stirred for another hour. Then the unreacted $\mathrm{SOCl}_{2}$ was removed. The solid residue was dissolved in $1 \mathrm{~mL}$ of DCM and the solution was further diluted in $1 \mathrm{~mL}$ of hexane. The diluted solution was then kept until it had evaporated to dryness, which produced white colored crystals. Next, $1.84 \mathrm{~g}$ (10 $\mathrm{mmol}$ ) of 3 was dissolved in $5 \mathrm{~mL}$ of dry THF. Then, $0.96 \mathrm{~g}$ (10 $\mathrm{mmol}$ ) of $\mathbf{1}$ was taken in $20 \mathrm{mM}$ of TEA. The solution of $\mathbf{1}$ was added drop wise into the solution of $\mathbf{3}$, and the mixture was stirred for $24 \mathrm{~h}$. The solution was extracted with brine solution and activated by $\mathrm{Na}_{2} \mathrm{SO}_{4}$ to obtain the desired product (PPY), which was further purified using column chromatography. ${ }^{1} \mathrm{H}-$ NMR (DMSO- $\left.d_{6}, 400 \mathrm{MHz}\right): 2.08\left(\mathrm{~s}, 3 \mathrm{H}, \mathrm{ArCH}_{3}\right), 2.23(\mathrm{~s}, 6 \mathrm{H}$, Py-2 $\mathrm{CH}_{3}$ ), 2.51 (solvent residual peak), 3.33 (due to trace $\mathrm{H}_{2} \mathrm{O}$ ), $5.14\left(\mathrm{~s}, 2 \mathrm{H}, \mathrm{CH}_{2}-\mathrm{Ar}\right), 5.86(\mathrm{~s}, 1 \mathrm{H}, \mathrm{Py}-\mathrm{C}=\mathrm{CH}), 6.98(\mathrm{~s}, 1 \mathrm{H}, \mathrm{ArH})$, $7.49(\mathrm{~s}, 1 \mathrm{H}, \mathrm{ArH}), 10.08(\mathrm{~s}, 1 \mathrm{H}, \mathrm{CH}=\mathrm{O}), 11.12(\mathrm{~s}, 1 \mathrm{H}, \mathrm{ArOH}) \mathrm{ppm}$. ${ }^{13} \mathrm{C}-\mathrm{NMR}$ (DMSO- $\left.d_{6}, 75 \mathrm{MHz}\right): 10.96,13.82,20.51,39.51-40.90$ (solvent residual peak), 46.51, 105.44, 121.82, 126.43, 129.27, 131.85, 136.95, 139.96, 139.79, 146.99, 156.36, 196.19 (Fig. S1 and S2, ESI $\dagger$ ). ESI-MS ${ }^{+}$for PPY in methanol: $m / z$ calc. for [PPY + H] $]^{+}: 245.281$, found: 245.221 (Fig. S3A, ESI $\dagger$ ).

\section{Generation of PPY/Al ${ }^{3+}$ in situ complex and its reaction with water}

For preparation of a stock solution of $\mathrm{AlCl}_{3}(1 \mathrm{mM})$, appropriate amounts of anhydrous $\mathrm{AlCl}_{3}$ were taken in different alcohol mediums and the mixture was vortexed until completely solubilized. Stock solutions of PPY (1 mM) in each alcohol medium were prepared separately. The alcohol medium was kept the same for the preparation of stock solutions and reaction medium. A portion $(10 \mu \mathrm{L}$ or $4 \mu \mathrm{L})$ of the stock solution of PPY (final concentration: $10 \mu \mathrm{M}$ or $2 \mu \mathrm{M}$ ) was added to each reaction medium (final volume $2 \mathrm{~mL}$ ) containing various amounts of $\mathrm{AlCl}_{3}(5-200 \mu \mathrm{M})$ in the absence or presence of water and/or $\mathrm{MeOH}$ in alcohol mediums under constant stirring, and the time-dependent $\mathrm{PPY} / \mathrm{Al}^{3+}$ complex formation kinetics were monitored using UV-vis absorption and fluorescence studies at $25{ }^{\circ}$ C. A diluted solution of PPY $\left./ \mathrm{Al}^{3+}(0.1 \mu \mathrm{M} \text { PPY }+5 \mu \mathrm{M} \mathrm{AlCl})_{3}\right)$ was used for the limit of detection (LOD) studies.

\section{UV-vis absorption and fluorescence studies}

The UV-vis absorption and fluorescence studies were carried out in a double beam spectrophotometer (TCC-240A, Shimadzu, Japan) and spectrofluorometer (LS 55, PerkinElmer). The fluorescence spectra were obtained upon excitation at $402 \mathrm{~nm}$ (excitation band-pass: 10 or 8 , and emission band pass: 2 or 8 ). Time-dependent fluorescence intensities at $505 \mathrm{~nm}$ were monitored for up to $60 \mathrm{~min}$ upon excitation at $405 \mathrm{~nm}$ while maintaining the same excitation and emission band-pass. The measuring solutions were filtered using a $0.45 \mathrm{~mm}$ filter (Millex, Millipore). The data reproducibility was checked using multiple measurements.

The LOD for $\mathrm{MeOH}$ was obtained as: ${ }^{36}$

$$
\text { Detection limit }(\mathrm{LOD})=3 \sigma / k \text {, }
$$

where $\sigma$, and $k$ represent the experimental standard deviation and slope value of the linear fitting, respectively. 
The fluorescence quantum yields were measured according to a procedure described earlier. ${ }^{37}$

\section{Theoretical calculations}

For structural optimization, density function theory (DFT) calculations were performed with the Gaussian 09 Program. ${ }^{38}$ Time-dependent DFT (TD-DFT) calculations were performed to obtain UV-vis absorption parameters of different species. The structural optimizations were carried out by considering the B3LYP exchange-correlation functional and the 6-31G basis function.

\section{Results and discussion}

\section{Probe design for $\mathrm{MeOH}$ detection}

The synthesis route of the $\mathrm{Al}^{3+}$ binding aldehydic phenol ligand consisting of a dangling pyrazole unit (PPY) is shown in Scheme 1. It has recently been reported that the $\mathrm{Al}^{3+}$ ion exhibits a strong complex formation affinity with phenolic Schiff-base molecules by binding to phenolic-O and imine- $\mathrm{N}$ in alcohol solvents, and the rest of the $\mathrm{Al}(\mathrm{III})$-coordination sites were filled by alcohol molecules. ${ }^{39}$ In this research, the aldehydic moiety was deliberately not converted into the corresponding imine functionality of PPY, in order to achieve a reduced complex formation affinity due to the weaker interaction ability of aldehydic-O than that of the imine-N. Thus, upon the addition of a trace amount of the $\mathrm{MeOH}$ in the $\mathrm{EtOH} /{ }^{i} \mathrm{PrOH}$ medium, a spontaneous conversion from a structurally fragile Td geometry to a relatively stable Oh symmetrical PPY/Al ${ }^{3+}$ complex is possible due to the exchange of coordinated $\mathrm{EtOH} /{ }^{i} \mathrm{PrOH}$ by $\mathrm{MeOH}$ molecules. The reaction of water with PPY $/ \mathrm{Al}^{3+}$ induces a fluorescence increase for the Oh species, but an intensity decrease for the $\mathrm{Td}$ complex. The $\mathrm{MeOH}$ induced the reversal of the fluorescence intensity change due to the change of the $\mathrm{Al}$ (III) geometry which was utilized for the detection of trace $\mathrm{MeOH}$ in $\mathrm{EtOH} /{ }^{i} \mathrm{PrOH}$.

\section{The PPY $/ \mathrm{Al}^{3+}$ complex formation and its interaction with} water

In the presence of anhydrous $\mathrm{AlCl}_{3}(200 \mu \mathrm{M})$, the UV-vis absorption intensity at $\sim 340 \mathrm{~nm}$ for PPY $(10 \mu \mathrm{M})$ in alcohol solvents decreased gradually with time (up to $60 \mathrm{~min}$ ), upon the formation of a new intensity at $405-410 \mathrm{~nm}$ through an isosbestic point at $\sim 378 \mathrm{~nm}$ (Fig. 1 and S4, ESI $\dagger$ ), indicating that PPY was involved in a complex formation reaction with the $\mathrm{Al}^{3+}$ ion by a kinetically slow process. The amount of complex formation was evaluated directly by judging the relative

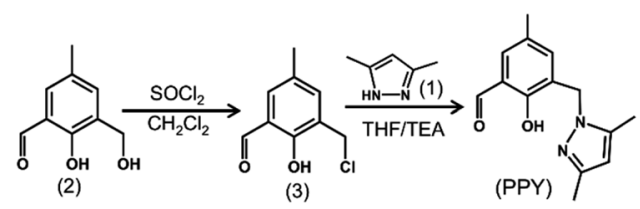

Scheme 1 Synthesis route of PPY.

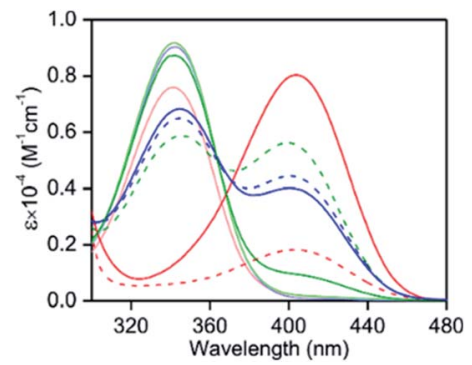

Fig. 1 The UV-vis absorption spectra of PPY $(10 \mu \mathrm{M})$ in the presence (solid lines) and absence (broken lines) of $2.5 \%(\mathrm{v} / \mathrm{v})$ water containing anhydrous $\mathrm{AlCl}_{3}(200 \mu \mathrm{M})$ at $25^{\circ} \mathrm{C}$ : red, $\mathrm{MeOH}$; blue, $\mathrm{EtOH}$ and green, ${ }^{i} \mathrm{PrOH}$. The spectra were collected during the 60 min of $\mathrm{AlCl}_{3}$ addition. The spectra of PPY in the absence of $\mathrm{AlCl}_{3}$ and water are depicted in their respective light colors for comparison.

intensity changeover from $\sim 340 \mathrm{~nm}$ to the $405-410 \mathrm{~nm}$ absorption band, because both intensities are not overlapped by each other (Fig. 1). However, to estimate the equilibrium between PPY and its $\mathrm{Al}(\mathrm{III})$-complex in the presence of various amount of $\mathrm{AlCl}_{3}(20-200 \mu \mathrm{M})$, the intensity values when the reaction attained equilibrium in nearly in 60 min were evaluated (Fig. 1 and S5, ESI $\dagger$ ). It should be noted that a large amount of $\mathrm{Al}^{3+}(\sim 200 \mu \mathrm{M}, 20$ equiv.) was required to react all the PPY with $\mathrm{Al}^{3+}$ in an MeOH medium (Fig. 1 and S5, ESI $\dagger$ ), which suggested that the interaction of PPY with the $\mathrm{Al}^{3+}$ ions was not only kinetically slow but also thermodynamically weak in nature. However, large fractions of unreacted PPY $\sim 60 \%$ in EtOH and $\sim 50 \%$ in ${ }^{i} \mathrm{PrOH}$ medium were identified in the presence of the same concentration of $\mathrm{Al}^{3+}$ (20 equiv.) (Fig. 1). This result indicates that the complex formation affinity was reduced even more in the $\mathrm{EtOH} /{ }^{i} \mathrm{PrOH}$ than in the $\mathrm{MeOH}$ medium.

In spite of inadequate complex formation in the EtOH or ${ }^{i} \mathrm{PrOH}$ solvents, the intensity at $\sim 405 \mathrm{~nm}$ for the $\mathrm{PPY} / \mathrm{Al}^{3+}$ complex was $\sim 3$-fold larger, i.e., there was a 6-7 times higher molar extinction coefficient $(\varepsilon)$ value $\left(\sim 1.1 \times 10^{4} \mathrm{M}^{-1} \mathrm{~cm}^{-1}\right)$, than that observed in $\mathrm{MeOH}\left(\sim 0.17 \times 10^{4} \mathrm{M}^{-1} \mathrm{~cm}^{-1}\right)$ (Fig. 1). Although phenolate-O and $\mathrm{Al}^{3+}$ bond formation was quite obvious, the formation of aldehydic-O with the $\mathrm{Al}^{3+}$ bond was
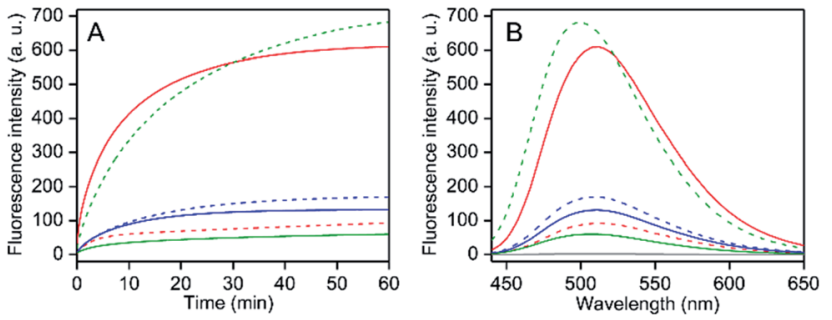

Fig. 2 (A) Time-dependent fluorescence intensity changes at $505 \mathrm{~nm}$ upon the addition of anhydrous $\mathrm{AlCl}_{3}$ addition $(50 \mu \mathrm{M})$, and (B) fluorescence spectra in 60 min of $\mathrm{AlCl}_{3}$ addition in various alcohol solvents in the presence (solid line) and absence (broken line) of $2.5 \%(\mathrm{v} / \mathrm{v})$ water containing PPY $(2 \mu \mathrm{M})$ at $25^{\circ} \mathrm{C}$ : red, $\mathrm{MeOH}$; blue, EtOH and green, ${ }^{i} \mathrm{PrOH}$. The spectrum in the absence of PPY is shown in grey (B). The excitation wavelengths were $405 \mathrm{~nm}$ in both (A and B). 
assured by an up-field ${ }^{1} \mathrm{H}-\mathrm{NMR}$ chemical shift from $\sim 9.91$ to $9.53 \mathrm{ppm}$, which was presumably due to an $\mathrm{Al}^{3+}$ binding induced, increased negative charge density at the aldehydic-O (Fig. S6 and S7 ESI, $\uparrow$ compare with the theoretical calculation section). Furthermore, a $1: 1 \mathrm{PPY}$ to $\mathrm{Al}^{3+}$ binding with a reflection of coordinated alcohol molecules (maximum up to four $\mathrm{MeOH}$ molecules $\left(\mathrm{m} / z\right.$ calc. for $[\mathrm{PPY}+4 \mathrm{MeOH}+\mathrm{Al}+\mathrm{Cl}]^{+}$: 433.873, found: 433.912$)$ and two EtOH molecules $(\mathrm{m} / \mathrm{z}$ calc. for $[\mathrm{PPY}+2 \mathrm{EtOH}+\mathrm{Al}+\mathrm{Cl}]^{+}:$397.854, found: 397.823)) were recognized in the ESI-MS ${ }^{+}$studies (Fig. S3B and D ESI $\dagger$ )). The results indicated that the saturation of the $\mathrm{Al}(\mathrm{III})$-coordination was effected by the solvent alcohol molecules. The reaction of $\mathrm{MeOH}\left(1-20 \%(\mathrm{v} / \mathrm{v})\right.$ with the solvent coordinated PPY/Al ${ }^{3+}$ in the presence of unreacted PPY in $\mathrm{EtOH} /{ }^{i} \mathrm{PrOH}$ showed a gradual decrease of both UV-vis intensities at $\sim 340 \mathrm{~nm}$ of unreacted PPY and at $\sim 403 \mathrm{~nm}$ of the PPY/Al ${ }^{3+}$ complex due to newly formed $\mathrm{MeOH}$ coordinated complexes and a replacement of coordinated $\mathrm{EtOH} /{ }^{i} \mathrm{PrOH}$ by $\mathrm{MeOH}$ molecules in the solvent coordinated PPY $/ \mathrm{Al}^{3+}$, respectively, (Fig. S8, ESI $\dagger$ ). The results justified the proposition that the stability or formation affinity was higher for $\mathrm{MeOH}$ coordinated $\mathrm{PPY} / \mathrm{Al}^{3+}$ than for the $\mathrm{EtOH} /{ }^{i} \mathrm{PrOH}$ coordinated one.

The interaction of the $\mathrm{PPY} / \mathrm{Al}^{3+}$ complex with water molecules in $\mathrm{EtOH} /{ }^{i} \mathrm{PrOH}$ medium showed an increase of absorption intensity at $\sim 340 \mathrm{~nm}$ whereas a decrease in intensity at $\sim 405 \mathrm{~nm}$ indicated the dissociation of the complex (Fig. S9, ESI $\dagger$ ). However, a similar water interaction in the $\mathrm{MeOH}$ medium caused a large increase of absorption intensity $(\sim 4$ fold) at $405 \mathrm{~nm}$ without generating any absorption band at $\sim 340 \mathrm{~nm}$ for free PPY (Fig. 1). This result shows that water reacted with the $\mathrm{Al}(\mathrm{III})$ center in the $\mathrm{MeOH}$ coordinated $\mathrm{PPY} / \mathrm{Al}^{3+}$ complex without disturbing the PPY and $\mathrm{Al}$ (III) interaction. Because of the greater stabilities of $\mathrm{MeOH}$ coordinated species, an incorporation of a water molecule in the $\mathrm{Al}(\mathrm{III})$ coordination site may occur by it replacing one coordinated $\mathrm{MeOH}$ molecule, and this phenomenon was verified from the ESI-MS ${ }^{+}$measurements $\left(\mathrm{m} / \mathrm{z}\right.$ calc. for $\left[\mathrm{PPY}+3 \mathrm{MeOH}+\mathrm{H}_{2} \mathrm{O}+\mathrm{Al}+\mathrm{Cl}\right]^{+}: 419.842$, found: 419.762) (Fig. S3C, ESI†).

\section{Solvent alcohol/water induced fluorescence response for PPY/} $\mathbf{A l}^{3+}$

The PPY exhibited no fluorescence intensity. With an addition of $\mathrm{AlCl}_{3}(50 \mu \mathrm{M}, 25$ equiv. $)$ in separate different alcohol mediums ( $\mathrm{MeOH}$, EtOH or $\left.{ }^{i} \mathrm{PrOH}\right)$ containing PPY $(2 \mu \mathrm{M})$, the fluorescence intensity at $\sim 510 \mathrm{~nm}$ was enhanced gradually with time until the intensity was nearly saturated in $\sim 60 \mathrm{~min}$ of $\mathrm{Al}^{3+}$ addition (Fig. 2A). However, the saturated intensity value varied widely depending on the alcohol medium. Compared to $\mathrm{MeOH}$, $\sim 8$ - and 2-fold larger intensities were detected in ${ }^{i} \mathrm{PrOH}$ and EtOH, respectively, $\left(\phi_{\mathrm{F}} \sim 0.013\right.$ for $\mathrm{MeOH}, \sim 0.025$ for EtOH, and $\sim 0.102$ for ${ }^{i} \mathrm{PrOH}$ ) (Fig. 2). Interestingly, the interaction of water with the PPY $/ \mathrm{Al}^{3+}$ complex exhibited an increase of intensity in the $\mathrm{MeOH}$ medium but an intensity decrease in the EtOH $/{ }^{i} \mathrm{PrOH}$ medium (Fig. 2). An intensity increase of about 6-fold was observed in the $\mathrm{MeOH}$ medium containing $\sim 1.2 \%(\mathrm{v} / \mathrm{v})$ water, whereas the intensity increased maximally up to $\sim 6.7$-fold $\left(\phi_{\mathrm{F}} \sim\right.$

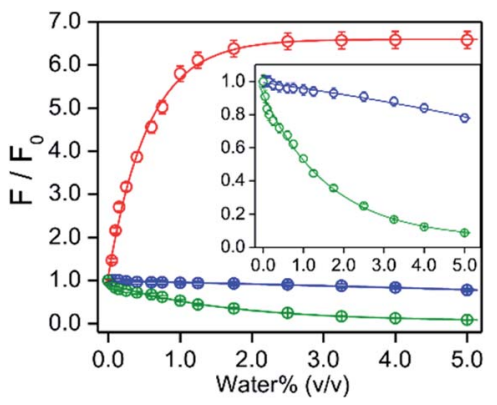

Fig. 3 The ratio of fluorescence intensities at $505 \mathrm{~nm}$ for the PPY/Al ${ }^{3+}$ complex in the presence of various amounts of water\% and its absence are plotted with the value of water\% $(\mathrm{v} / \mathrm{v})$ in different alcohol mediums at $25^{\circ} \mathrm{C}$ : red, $\mathrm{MeOH}$; blue, $\mathrm{EtOH}$ and green, ${ }^{i} \mathrm{PrOH}$. The intensity values in the absence and presence of different water\% are collected in 60 min of anhydrous $\mathrm{AlCl}_{3}(50 \mu \mathrm{M})$ addition in the medium containing PPY $(2 \mu \mathrm{M})$. Inset: the $Y$-axis expanded plots for $\mathrm{EtOH}$ and ${ }^{i} \mathrm{PrOH}$ medium are shown for clarity. Excitation and emission wavelength were 405 and $505 \mathrm{~nm}$, respectively. The data points for each alcohol solvent are fitted using a single exponentially-fitted method. The average value for each data point is obtained from triplicate measurements $(n=3)$.

0.09 ) in the presence of $\sim 2.5 \%$ water (Fig. 3). In contrast, intensity quenching, almost completely in ${ }^{i} \mathrm{PrOH}$ and $\sim 20 \%$ in EtOH solvents was detected by the addition of $5 \%$ water (Fig. 3 ). Similarly to the $\mathrm{EtOH} /{ }^{i} \mathrm{PrOH}$ solvent, the water induced fluorescence decrease was noticed for other alcohols ( $n$-PrOH, ${ }^{t} \mathrm{BuOH}, n$-hexanol) (Fig. S10, ESI $\dagger$ ). Therefore, $\mathrm{MeOH}$ is a unique alcohol to use to show the water induced fluorescence increase.

\section{DFT theoretical calculations: complex structure vs. optical response}

The $\mathrm{Al}(\mathrm{III})$ can exist as both $\mathrm{Oh}$ and $\mathrm{Td}$ geometric forms, ${ }^{\mathbf{4 0 - 4 2}}$ where the Oh symmetry is more preferred than the Td symmetry. ${ }^{\mathbf{4 1 , 4 2}}$ According to the results of the ESI-MS ${ }^{+}$studies, coordination of four $\mathrm{MeOH}$ and two $\mathrm{EtOH}$ molecules in the respective solvents were identified (Fig. S3, ESI $\dagger$ ). Because PPY was acting as $1: 1$ bi-dentate ligand for $\mathrm{Al}^{3+}$, the coordination of the four $\mathrm{MeOH}$ molecules was related to the Oh geometry of $\mathrm{Al}(\mathrm{III})$. However, the same number of alcohol molecules binding for bigger EtOH or ${ }^{i} \mathrm{PrOH}$ or any other alcohol molecules may not be a steric fit around the $\mathrm{Al}(\mathrm{III})$ coordination sphere, thus a less stable Td structure which would allow two $\mathrm{EtOH} /{ }^{i} \mathrm{PrOH}$ molecules was the most likely to occur (Scheme 2).

Using a DFT based theoretical calculation, it was identified that a possible Oh to Td structural interconversion for PPY/Al ${ }^{3+}$ was responsible for the alcoholic solvent dependent changes in UV-vis absorption and fluorescence properties, both in the presence and absence of water. The ground state geometries of four $\mathrm{MeOH}$ and two $\mathrm{EtOH} /{ }^{i} \mathrm{PrOH}$ molecules coordinated $\mathrm{Oh}$ and Td complexes, respectively, with common phenolic-O and aldehydic-O coordination were optimized using B3LYP density function and a 6-31G basis set. The UV-vis absorption properties for the Oh and Td structures were evaluated using the TD-DFT calculations on the optimized ground state structures. The calculated HOMO to LUMO electronic transitions at $\sim 409 \mathrm{~nm}$ 
for both $\mathrm{Oh}$ and $\mathrm{Td}$ structures corresponded well with the respective experimental absorption wavelengths (Fig. 1, 4 and Scheme 2). In a similar way to the experimentally observed UVvis intensity increase at $\sim 405 \mathrm{~nm}$ obtained by changing the solvent medium from $\mathrm{MeOH}$ to $\mathrm{EtOH} /{ }^{i} \mathrm{PrOH}$, the $\mathrm{HOMO} \rightarrow$ LUMO oscillator strength $\left(f_{\text {cal }}\right)$ for the $\mathrm{MeOH}$ coordinated $\mathrm{Oh}$ geometry $(\sim 0.04)$ was found to be significantly lower than that detected for the EtOH $/{ }^{i} \mathrm{PrOH}$ coordinated Td geometry $(\sim 0.07)$ (Fig. 4). When one coordinated $\mathrm{MeOH}$ close to the pyrazole-N was replaced by a water molecule, the optimized structure showed a proton transfer reaction from the coordinated water molecule to pyrazole- $\mathrm{N}$, and a large increase of $f_{\text {cal }}$ from $\sim 0.04$ to 0.09 was detected (Fig. 4 and Scheme 2). The increase of $f_{\text {cal }}$ agreed well with the experimentally observed water induced large increase of UV-vis intensity in the MeOH medium (Fig. 1).

The efficient PET process from the pyrazole unit to the aldehydic phenol chromophore moiety made the PPY nonfluorescent (Fig. S11, ESI $\dagger$ ). For the $\mathrm{MeOH}$ coordinated Oh structure, the PET process did not disturb it significantly, and thus a weak fluorescence intensity was observed experimentally (Fig. 2 and 4). However, the electron distribution in both HOMO and LUMO for EtOH or ${ }^{i} \mathrm{PrOH}$ coordinated Td-species centered mostly at the aldehydic phenol chromophore, and the resultant suppression of the PET process made the Td complex highly fluorescent (Fig. 2, 4 and Scheme 2). Most interestingly, the calculations also identified that the PET process in the water substituted Oh species was eliminated, which clarified the probable reason for the water induced large increase of fluorescence intensity in the $\mathrm{MeOH}$ medium. All these studies suggested that the change of $\mathrm{Al}(\mathrm{III})$ geometry from $\mathrm{Oh}$ to $\mathrm{Td}$ may

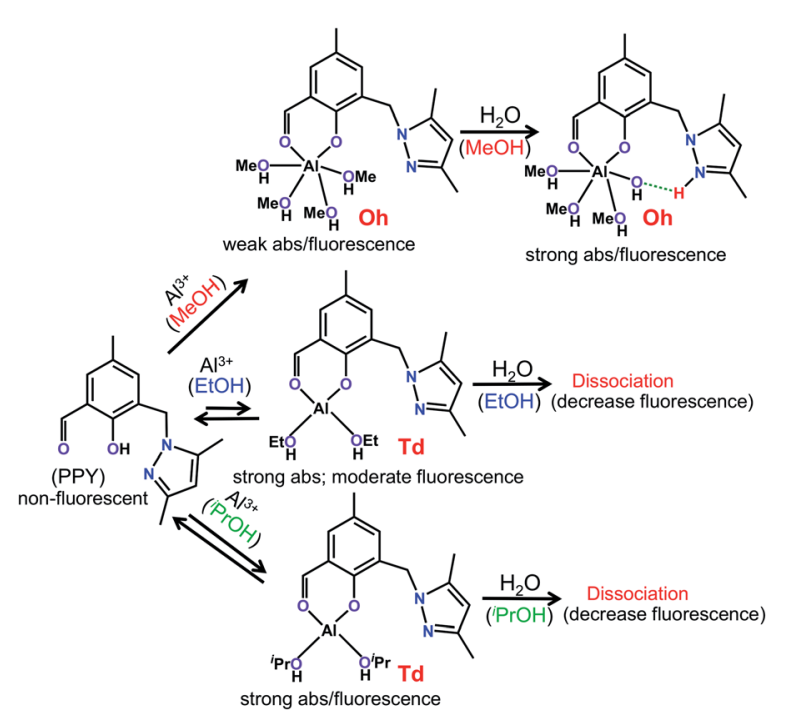

Scheme 2 Mechanistic view of alcoholic solvent selective formation of geometrically different PPY/Al ${ }^{3+}$ complexes and their reaction with water molecules. The Al(III) coordination saturation for the octahedral (Oh) geometry in $\mathrm{MeOH}$ and the tetrahedral (Td) geometry in EtO$\mathrm{H} /{ }^{i} \mathrm{PrOH}$ medium are achieved by the coordination of four $\mathrm{MeOH}$ and two EtOH/iPrOH molecules, respectively. The coordination geometry dependent relative UV-vis absorption (abs), and the emission parameters of the PPY/Al ${ }^{3+}$ complex are shown. be responsible for the alcohol solvent dependent change in optical response for the PPY/Al ${ }^{3+}$ complex.

\section{Detection of $\mathrm{MeOH}$ in EtOH or ${ }^{i} \mathrm{PrOH}$ in the presence of water}

It was found that the addition of water induced a fluorescence increase for $\mathrm{MeOH}$ coordinated $\mathrm{Oh} \mathrm{PPY} / \mathrm{Al}^{3+}$, whereas the intensity decreased for the $\mathrm{EtOH} /{ }^{i} \mathrm{PrOH}$ coordinated $\mathrm{Td}$ complex (Fig. 3). An intensity increase of about 6.7-fold was found in $\mathrm{MeOH} /$ water mixed medium, which remained unaffected within a water\% of $\sim 2.5 \%-11.0 \%(\mathrm{v} / \mathrm{v})$, although the intensity decreased gradually as the water\% was further increased (Fig. 3 and S12, ESI $\dagger$ ). However, for the water\% amount above $\sim 75 \%$, the intensity value was found to be less in comparison to that observed in the absence of water (Fig. S12, $\mathrm{ESI} \dagger)$. It was also observed that the coordinated solvent in the $\mathrm{PPY} / \mathrm{Al}^{3+}$ complex were replaced by $\mathrm{MeOH}$ from the EtOH$/{ }^{i} \mathrm{PrOH}$ molecules with a subsequent change of complex geometry from $\mathrm{Td}$ to $\mathrm{Oh}$ by the addition of $\mathrm{MeOH}$ in $\mathrm{EtOH} /{ }^{i} \mathrm{PrOH}$ (Fig. 2, Scheme 2, and Fig. S8, ESI $\dagger$ ). Additionally, the residual unreacted PPY existed after the completion of a complex formation in $\mathrm{EtOH} /{ }^{i} \mathrm{PrOH}$ medium reacted further with $\mathrm{Al}^{3+}$ to form $\mathrm{MeOH}$ coordinated $\mathrm{PPY} / \mathrm{Al}^{3+}$ in the presence of $\mathrm{MeOH}$ (Fig. S8, ESI $\dagger$ ). Moreover, the presence of $10 \% \mathrm{MeOH}$ in the solution with various $\mathrm{EtOH} /{ }^{i} \mathrm{PrOH}$ to water ratios showed that the presence of water effected different extents of intensity increase up to $70 \%$ water (Fig. S13, ESI $\dagger$ ). All these results strongly suggest that the relative percentage of $\mathrm{MeOH}$

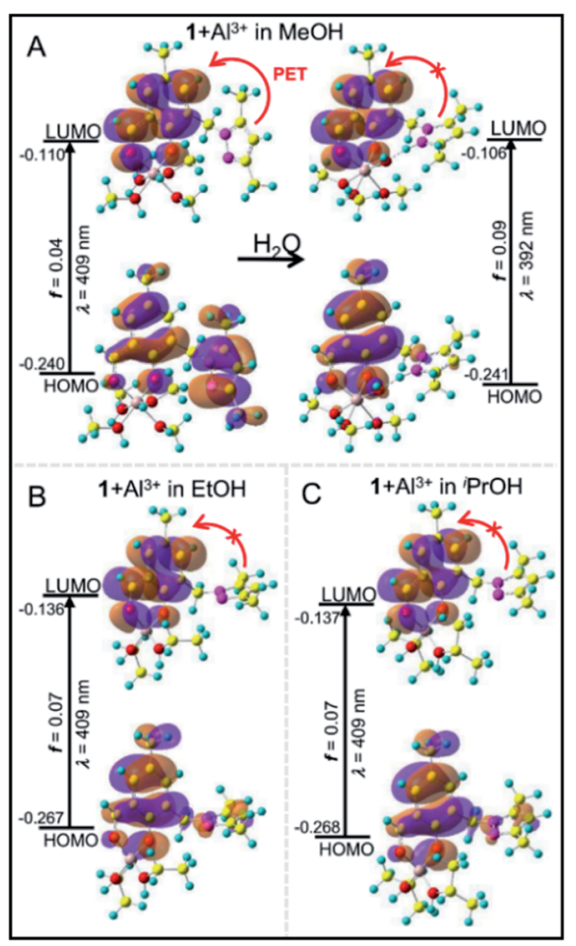

Fig. 4 Frontier molecular orbital (FMO) profiles including different calculated UV-vis absorption parameters of $\mathrm{MeOH}$ (A: left upper panel) and $\mathrm{MeOH} / \mathrm{H}_{2} \mathrm{O}$ (A: right upper panel) coordinated Oh. The EtOH (B: left lower panel) and ${ }^{i} \mathrm{PrOH}$ (C: right lower panel) coordinated $\mathrm{Td}$ complexes based on DFT and TD-DFT (B3LYP/6-31G) calculations. 
coordinated Oh complex with respect to the EtOH $/{ }^{i} \mathrm{PrOH}$ coordinated Td species should be much higher even in the presence of a low amount of $\mathrm{MeOH}$ in $\mathrm{EtOH} /{ }^{i} \mathrm{PrOH}$. The water effected fluorescence intensity increased in the presence of various $\mathrm{MeOH}$ amounts was investigated for its potential use in the analytical detection of $\mathrm{MeOH}$ in $\mathrm{EtOH} /{ }^{i} \mathrm{PrOH}$.

In the $\mathrm{EtOH} /{ }^{i} \mathrm{PrOH}$ medium containing water, the intensity ratios between the presence and absence of $\mathrm{MeOH}$ increased gradually with the increase of $\mathrm{MeOH} \%(0.5-10 \%(\mathrm{v} / \mathrm{v}))$ when the amount of any fixed water\% value was within $2.5-55 \%$ (Fig. 5 and S14, ESI $\dagger$ ). The relative intensity enhancements depended on the water\%. For a solution containing $10 \% \mathrm{MeOH}$, the relative intensity increments were $\sim 2.0-, 3.1-, 2.5$ - and 1.5 -fold for the EtOH system or $\sim 1.8-, 3.7-, 3.5$ - and 2.2-fold for the ${ }^{i}$ PrOH system in the presence of $2.5 \%, 10 \%, 25 \%$, and $55 \%(\mathrm{v} / \mathrm{v})$ of water, respectively (Fig. 5). The extent of the relative intensity increase with increasing $\mathrm{MeOH} \%$ under various water\% (2.5$55 \%$ ) values followed a fairly good linear correlation (residual of fitting $\chi^{2} \sim 0.99$ ) for both the EtOH and ${ }^{i} \mathrm{PrOH}$ systems, where the water\% dependent slope values were estimated to be $\sim 0.10$, $0.21,0.15$ and 0.08 for EtOH or $\sim 0.08,0.26,0.25$ and 0.12 for ${ }^{i} \mathrm{PrOH}$ in the presence of $2.5 \%, 10 \%, 25 \%$ and $55 \%$ water, respectively (Fig. 5). Using the linear calibration curve, the unknown amount of $\mathrm{MeOH}$ in the $\mathrm{EtOH} /{ }^{i} \mathrm{PrOH}$ solvent containing various water\% can be evaluated ratiometrically. It was evident that the water amount present in the solution played the most critical role for the $\mathrm{MeOH}$ detection sensitivity, in which the sensitivity was at maximum at a water amount of $\sim 10 \%(\mathrm{v} / \mathrm{v})$ for both EtOH and ${ }^{i} \mathrm{PrOH}$. Notably, the $\mathrm{MeOH}(10 \% \mathrm{v} / \mathrm{v})$ also induced an appreciable amount of increased fluorescence intensity for $\mathrm{PPY} / \mathrm{Al}^{3+}$ and this was also observed in other alcohol mediums ( $n$-PrOH, ${ }^{t} \mathrm{BuOH}$ and $n$-hexanol) containing $5 \%$ water (Fig. S15, ESI $\dagger$ ), which indicated that the $\mathrm{MeOH}$ detection selectivity of the PPY/Al ${ }^{3+}$ complex did not alter with the change of alcohol systems. However, to detect a low amount of $\mathrm{MeOH}$ or low LOD values, fluorescence studies were
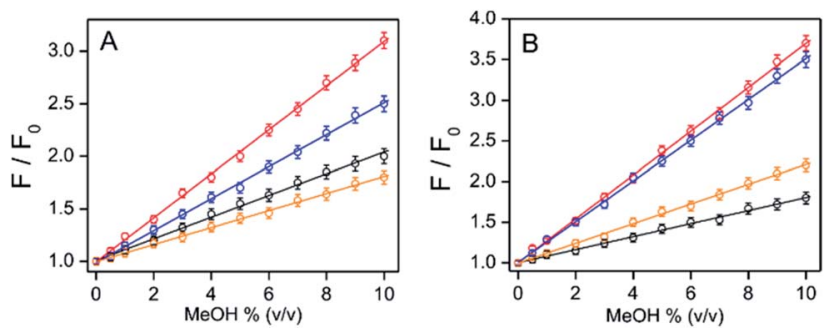

Fig. 5 Relative fluorescence intensity changes between the presence and absence of $\mathrm{MeOH}$ for PPY/Al ${ }^{3+}$ are plotted with $\mathrm{MeOH} \%(\mathrm{v} / \mathrm{v})$ in $(\mathrm{A})$ $\mathrm{EtOH} /$ water and (B) ${ }^{i} \mathrm{PrOH} /$ water mixed medium containing various amounts of water\% (v/v): black, $2.5 \%$; red, $10 \%$; blue, $25 \%$; orange, $55 \%$. The identical value of water\% before and after the $\mathrm{MeOH}$ spike was maintained by an addition of an appropriate amount of water in the spiked sample. The intensity values in the absence and presence of various $\mathrm{MeOH} \%$ were collected during the addition of $\mathrm{AlCl}_{3}(50 \mu \mathrm{M})$, over $60 \mathrm{~min}$, to the medium containing PPY $(2 \mu \mathrm{M})$. The data points for each solvent system are fitted with a linear equation. Excitation and emission wavelengths were $405 \mathrm{~nm}$ and $505 \mathrm{~nm}$. The average value for each data point is obtained from triplicate measurements $(n=3)$. conducted in the presence of very low PPY/Al ${ }^{3+}$ concentrations $\left(0.1 \mu \mathrm{M}\right.$ PPY and $\left.4 \mu \mathrm{M} \mathrm{Al}^{3+}\right)$ so that an appreciable fluorescence response can be observed even in the presence of much lower amount of $\mathrm{MeOH}$. The fluorescence intensity changes in the presence of much lower amounts of $\mathrm{MeOH}(0.05-0.30 \%)$ are shown in Fig. S16 (ESI†). The LOD was evaluated using the equation: $\mathrm{LOD}=3 \sigma / k$ (see Experimental section). The LOD values for $\mathrm{MeOH}$ detection were estimated to be $\sim 0.03 \%-0.06 \%$ depending on the solvent compositions.

The water\% dependency variation of the fluorescence response for $\mathrm{MeOH}$ was interpreted by combining the water\% dependent various extent of intensity increase for $\mathrm{MeOH}$ medium in the absence of $\mathrm{EtOH} /{ }^{i} \mathrm{PrOH}$ and the intensity decrease for $\mathrm{EtOH} /{ }^{i} \mathrm{PrOH}$ in the absence of $\mathrm{MeOH}$ (Fig. 3 and S12, ESI $\dagger$ ). The presence of a small amount of $\mathrm{MeOH}$ in the $\mathrm{EtOH} /{ }^{i} \mathrm{PrOH}$ medium replaced coordinated EtOH $/{ }^{i} \mathrm{PrOH}$ with $\mathrm{MeOH}$ molecules in PPY/Al ${ }^{3+}$ to obtain a Td to Oh structural change. However, the existence of an $\mathrm{EtOH} /{ }^{i} \mathrm{PrOH}$ coordinated Td complex and its water interaction induced intensity decrease cannot be neglected entirely in the interpretation of the fluorescence response values in the presence of various amounts of $\mathrm{MeOH}$ and water. The presence of a water induced $\sim 6.7$-fold intensity increase remains unchanged between $2.5 \%$ and $10 \%$ of water for $\mathrm{MeOH}$ in the absence of $\mathrm{EtOH} /{ }^{i} \mathrm{PrOH}$ (Fig. 3 and S12, ESI $\dagger$ ) and the observed intensity was decreased by increasing the water\% (2.5\% to $10 \%)$ for $\mathrm{EtOH} /{ }^{i} \mathrm{PrOH}$ in the absence of $\mathrm{MeOH}$, which effects the enlargement of the $\mathrm{MeOH}$ detection slope value ( $\sim 0.10$ to 0.21 for EtOH and $\sim 0.08$ to 0.26 for ${ }^{i} \mathrm{PrOH}$ ) by the increase of water\%. Significantly higher slope changes for ${ }^{i} \mathrm{PrOH}$ medium: $\sim 3.7$-fold compared to $\sim 2.1$-fold for EtOH medium due to the increase of water\% (2.5\% to $10 \%)$ was rationalized by the increased water amount which induced a greater amount of intensity quenching for ${ }^{i} \mathrm{PrOH}(\sim 90 \%)$ than the EtOH medium (45\%) in the absence of $\mathrm{MeOH}$ (Fig. 5 and S12, ESI $\dagger$ ). However, any further increase of water $\%$ from $10 \%$ to $55 \%$ produced a larger intensity decrease for $\mathrm{MeOH}$ in the absence of $\mathrm{EtOH} /{ }^{i} \mathrm{PrOH}$ than for $\mathrm{EtOH} /{ }^{i} \mathrm{PrOH}$ in the absence of $\mathrm{MeOH}$ (Fig. S12, ESI $\dagger$ ), and thus a gradual decrease of the $\mathrm{MeOH}$ detection slope value from $\sim 0.21$ to 0.08 for EtOH and $\sim 0.26$ to 0.12 for ${ }^{i} \mathrm{PrOH}$ was observed.

\section{The $\mathrm{MeOH}$ detection in alcoholic samples and sanitizers}

The EtOH $\%$ in alcoholic beverages are dependent (5-70\% (v/v)) on their classifications, and usually water is the rest of the liquid volume. However, according to WHO guidelines, the composition of hand sanitizers should be $\sim 80 \% \mathrm{EtOH}(\mathrm{v} / \mathrm{v})$ or $75 \%{ }^{i} \operatorname{PrOH}(\mathrm{v} / \mathrm{v})$, glycerol $(1.45 \%(\mathrm{v} / \mathrm{v}))$, and $\mathrm{H}_{2} \mathrm{O}_{2}(0.125 \%(\mathrm{v} /$ v)). ${ }^{43}$ Spiked $\mathrm{MeOH} \%$ in high and low EtOH\% containing vodkas $(\sim 45 \%(\mathrm{v} / \mathrm{v}))$ and wine $(\sim 15 \%(\mathrm{v} / \mathrm{v}))$ samples, respectively, were estimated. As the $\mathrm{MeOH}$ detection sensitivity at above $55 \%(\mathrm{v} / \mathrm{v})$ of water was comparatively low (Fig. S12 and S13, ESI $†$ ), an external EtOH addition is required for the detection of $\mathrm{MeOH}$ in the wine samples. In addition, spiked $\mathrm{MeOH}$ was estimated both in the presence and absence of externally added EtOH to show the applicability of the method for alcoholic beverages containing higher $\mathrm{EtOH} \%$. However, the 
spiked $\mathrm{MeOH}$ amounts were estimated in $\mathrm{EtOH}-$ and ${ }^{i} \mathrm{PrOH}-$ based hand sanitizers without any further addition of external $\mathrm{EtOH} /{ }^{i} \mathrm{PrOH}$.

To observe the $\mathrm{MeOH}$ induced fluorescence intensity increase, the water\% before and after $\mathrm{MeOH}$ spikes in the hand sanitizer samples were maintained by addition of an appropriate amount of water in the spiked $\mathrm{MeOH}$ sample. With the increase of $\mathrm{MeOH}$ spikes from $0.5 \%$ to $10 \%$ in the vodka sample in the presence and absence of externally added $30 \% \mathrm{EtOH}$ (total water $\sim 25 \%$ ), the relative fluorescence intensity between the presence and absence of $\mathrm{MeOH}$ was found to increase linearly from 1.04 - to 1.77 -fold and 1.08 - to 2.45 -fold, respectively (Fig. 6A-C). For a wine sample with the externally added $30 \% \mathrm{EtOH}$, the relative intensity also increased linearly from 1.05- to 1.78-fold (Fig. S17, ESI $\dagger$ ), where the slope value of the linear plots $\sim 0.08$ was found to be similar to that obtained for
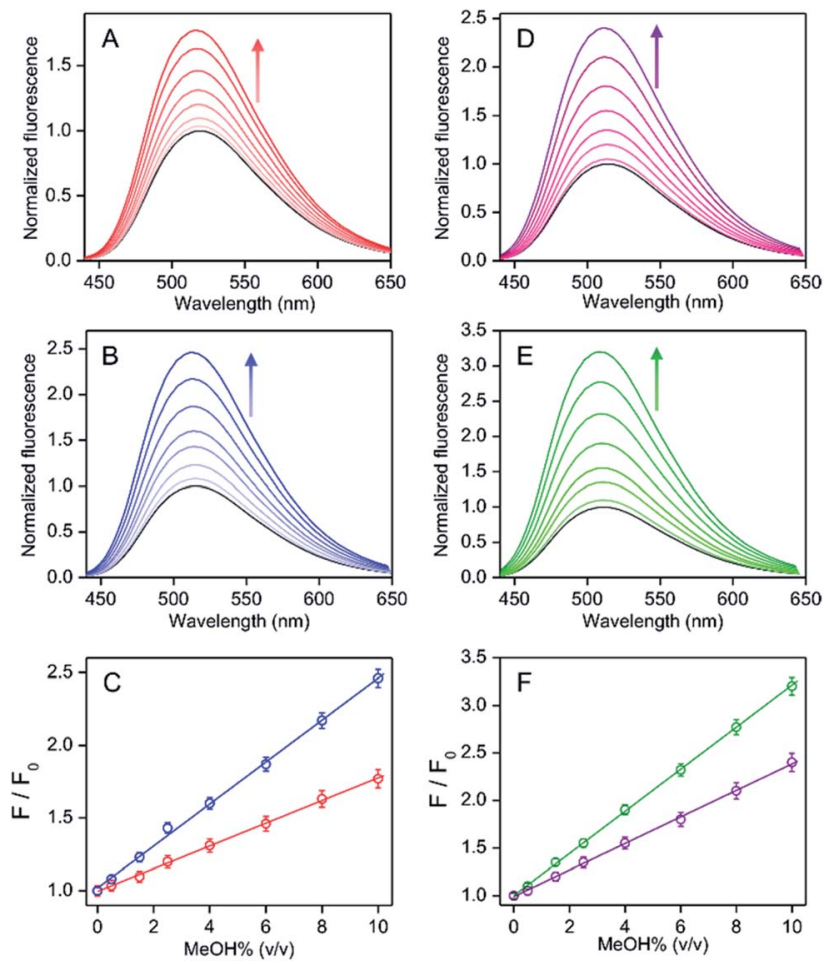

Fig. 6 The relative fluorescence spectral changes between the presence and absence of $\mathrm{MeOH}$ for $\mathrm{PPY} / \mathrm{Al}^{3+}$ with various $\mathrm{MeOH}$ spikes $(0.5-10 \%(v / v))$ in an alcoholic beverage (vodka: labelled EtOH\% $\sim 45 \%(\mathrm{v} / \mathrm{v}))$ in $(\mathrm{A})$ the absence and (B) the presence of externally added $30 \% \mathrm{EtOH}$, and (D) EtOH or (E) ${ }^{i} \mathrm{PrOH}$-based hand sanitizers (labelled ${ }^{i} \mathrm{PrOH} \sim 75 \%$ and $\mathrm{EtOH} \sim 80 \%$ ) at $25^{\circ} \mathrm{C}$. The spectra in the absence of $\mathrm{MeOH}$ spikes are shown in black. The maximum intensity values for alcoholic beverages (C) and hand sanitizer (F) samples are plotted against the amount of the $\mathrm{MeOH}$ spikes. (A-C) Blue and red correspond to the presence and absence of externally added $30 \% \mathrm{EtOH}$, respectively. (D-F) Purple and green correspond to $\mathrm{EtOH}-$ and ${ }^{i} \mathrm{PrOH}-$ based hand sanitizer, respectively. (A-F) The identical value of water\% before and after of $\mathrm{MeOH}$ spike was maintained by using an appropriate amount of water addition in the spiked sample. The intensity increases with the increase of $\mathrm{MeOH} \%$ are shown by arrows. The excitation wavelength was $405 \mathrm{~nm}$. The average value for each data point is obtained from triplicate measurements $(n=3)$. a known EtOH/water mixed medium ( $45 \% \mathrm{EtOH}$ ) or vodka ( $45 \%$ EtOH) sample (Fig. 5A). In addition, the slope values for vodka samples with $30 \%$ EtOH added externally (total EtOH, 75\%) were also similar to the results obtained for the known $75 \%$ EtOH medium (Fig. 5A, 6B and C). All these results clearly showed that the presence of other chemicals in alcoholic beverages did not disturb the detection ability of the MeOH. Even without knowing the accurate water\% value in the test sample, the estimation of $\mathrm{MeOH}$ contamination was possible from the correlation of fluorescence response of the test sample with the linear calibration plots for the corresponding $\mathrm{MeOH}$ free alcoholic beverages (Fig. 6C).

The fluorescence spectra for $\mathrm{PPY} / \mathrm{Al}^{3+}$ in $\mathrm{EtOH}(80 \%)$ or ${ }^{i} \mathrm{PrOH}(75 \%)$ and a water mixed medium remain unchanged by the addition of glycerol $(1.45 \%(\mathrm{v} / \mathrm{v}))$ or $\mathrm{H}_{2} \mathrm{O}_{2}(0.125 \%(\mathrm{v} / \mathrm{v}))$, both in the presence and absence of $\mathrm{MeOH}$ (Fig. S18, ESI $\dagger$ ), showing that the presence of glycerol and $\mathrm{H}_{2} \mathrm{O}_{2}$ in hand sanitizers did not affect the performance of the probe. The intensity increased linearly from $\sim 1.05$ to 2.38 for EtOH-based sanitizer or from $\sim 1.08$ to 3.22 for the ${ }^{i} \mathrm{PrOH}$-based sanitizer because of the increase of the amount of $\mathrm{MeOH}$ spiking from $0.5 \%$ to $10 \%$ under the identical water\% condition. The observed slope value of $\sim 0.22$ for the ${ }^{i} \mathrm{PrOH}$-based sanitizer and of $\sim 0.14$ for the EtOH-based sanitizer were similar to that detected for the known $80 \% \mathrm{EtOH}$ and $75 \%{ }^{i} \mathrm{PrOH}$ medium, respectively (Fig. 5 and 6D-F). Therefore, an unknown amount of $\mathrm{MeOH}$ contamination in hand sanitizers could be estimated by correlating the intensity value of the test sample with the known linear calibration line obtained for the $\mathrm{EtOH}$ ( ${ }^{i}{ }^{i} \mathrm{PrOH}$ ) containing water or $\mathrm{MeOH}$ free standard for the EtOH (or ${ }^{i} \mathrm{PrOH}$ )-based hand sanitizer.

As in the procedure described previously, a low level of $\mathrm{MeOH}$ contamination in alcoholic beverages and sanitizer could be estimated using a low probe concentration $(0.1 \mu \mathrm{M}$ PPY and $4 \mu \mathrm{M} \mathrm{Al}^{3+}$ ). The $\mathrm{MeOH}$ induced fluorescence spectral changes in the presence of a lower amount of $\mathrm{MeOH}$ spikes $\left(0.06-0.18 \%\right.$ for a vodka sample and $0.03-0.10 \%$ for the ${ }^{i} \mathrm{PrOH}$ hand sanitizer) revealed that even a $\mathrm{MeOH}$ contamination of below $0.1 \mu \mathrm{M}$ in alcoholic beverages and sanitizer can be estimated accurately by the present protocols (Fig. S19, ESI $\dagger$ ). The efficiency of probe recovery was also verified by conducting EDTA induced fluorescence intensity quenching studies in vodka and EtOH-based hand sanitizers. For both samples, $\mathrm{MeOH}$ induced $\sim 90 \%$ of the increased intensity for $\mathrm{PPY} / \mathrm{Al}^{3+}$ which was found to be quenched by the addition of EDTA, whereas the intensity recovered again upon further addition of $\mathrm{Al}^{3+}$ (Fig. S20, ESI $\dagger$ ). The EDTA induced displacement of PPY from the PPY $/ \mathrm{Al}^{3+}$ complex again participated in complexation with the freshly added $\mathrm{Al}^{3+}$ to regain the fluorescence intensity by the reaction with $\mathrm{MeOH}$ present in solution. Thus, the probe can be reused on several occasions.

\section{Conclusions}

A sensitive fluorometric $\mathrm{MeOH}$ detection method was demonstrated in $\mathrm{EtOH} /{ }^{i} \mathrm{PrOH}$ in a water medium using a $1: 1 \mathrm{Al}(\mathrm{III})-$ complex of an aldehydic phenol ligand containing a pyrazole 
unit (PPY). The complex adopted the $\mathrm{MeOH}$ coordinated weakly fluorescent octahedral (Oh) geometry from the fluorescent tetrahedral (Td) structure by an addition of $\mathrm{MeOH}$ in the EtO$\mathrm{H} /{ }^{i} \mathrm{PrOH}$. The interaction of water with the Oh species causes a large fluorescence intensity increase due to the exchange of one coordinated $\mathrm{MeOH}$ by a water molecule, whereas a similar water interaction for the $\mathrm{Td}$ complex resulted in an intensity decrease due to its dissociation. The water mediated fluorescence intensity reversal due to the change in complex geometries by the addition of $\mathrm{MeOH}$ was utilized to detect $\mathrm{MeOH}$ in $\mathrm{EtOH} /{ }^{i} \mathrm{PrOH}$ and various alcoholic beverages/hand sanitizers. Such water induced $\mathrm{MeOH}$ detection could be very useful industrially.

\section{Author contributions}

Snigdha Roy: experimental, analysis and review and editing. Sanju Das: synthesis. Ambarish Ray: conceptualization, supervision, editing. Partha Pratim Parui: experimental, conceptualization, writing - original draft, supervision.

\section{Conflicts of interest}

There are no conflicts of interest to declare.

\section{Acknowledgements}

This study is partially supported by UGC and the Government of West Bengal for financial support under the RUSA 2.0 scheme (PPP; No: 5400-F(Y)). SR wishes to acknowledge the UGC for the SRF fellowship. The authors also acknowledge Jadavpur University for use of their departmental facilities.

\section{Notes and references}

1 S. B. Jarwani, P. D. Motiani and S. Sachdev, J. Emerg. Trauma Shock, 2016, 6, 73.

2 G. A. Beauchamp and M. Valento, Emerg. Med. Pract., 2016, 18, 1.

3 R. Paasma, K. E. Hovda, A. Tikkerberi and D. Jacobsen, Clin. Toxicol., 2007, 45, 152.

4 F. Bindler, E. Voges and P. laugel, Food Addit. Contam., 1988, $5,343$.

5 P. E. Hantson, Bull Mem Acad R Med Belg, 2006, 161, 425.

6 D. G. Barceloux, G. R. Bond, E. P. Krenzelok, H. Cooper and J. A. Vale, J. Toxicol. Clin. Toxicol., 2002, 40, 415.

7 J. J. Liu, M. R. Daya and N. C. Mann, J. Toxicol., Clin. Toxicol., 1999, 37, 69.

8 F. Onder, S. Ilker, T. Kansu, T. Tatar and G. Kural, Int. Ophthalmol., 1998, 22, 81.

9 J. A. Kruse, Crit. Care Clin., 2012, 28, 661.

10 C. S. Moon, Ann Occup Environ Med, 2017, 29, 44.

11 D. Jacobsen and K. E. McMartin, Med. Toxicol., 1986, 1, 309.
12 L. Welle, A. Medoro and B. Warrick, Ann. Emerg. Med., 2021, 77, 131.

13 P. F. Pereira, R. M. F. Sousa, R. A. A. Munoz and E. M. Richter, Fuel, 2013, 103, 725.

14 Methanol: colorless, $\mathrm{mp}=-97.0^{\circ} \mathrm{C}$, bp $=64.7^{\circ} \mathrm{C}, d=0.79 \mathrm{~g}$ $\mathrm{dm}^{3}, n_{\mathrm{D}}\left(\right.$ at $\left.20^{\circ} \mathrm{C}\right)=1.33$, dipole moment $=1.70 \mathrm{D}$, dielectric constant $=33, \mathrm{p} K_{\mathrm{a}}=15.5$.

15 Ethanol: colorless, $\mathrm{mp}=-114.3{ }^{\circ} \mathrm{C}$, bp $=78.4{ }^{\circ} \mathrm{C}, d=$ $0.799 \mathrm{~g} \mathrm{dm}^{3}, n_{\mathrm{D}}\left(\right.$ at $\left.20{ }^{\circ} \mathrm{C}\right)=1.36$, dipole moment $=1.69$ $\mathrm{D}$, dielectric constant $=24.6, \mathrm{p} K_{\mathrm{a}}=15.9$.

16 G. J. Mohr, F. Lehmann, U. W. Grummt and U. E. SpichigerKeller, Anal. Chim. Acta, 1997, 344, 215.

17 S. H. Lim, L. Feng, J. W. Kemling, C. J. Musto and K. S. S. Suslick, Nat. Chem., 2009, 1, 562.

18 T. Qin, B. Liu, Y. Huang, K. Yang, K. Zhu, Z. Luo, C. Pan and L. Wang, Sens. Actuators, B, 2018, 277, 484.

19 L. R. Cordell, H. Pandya, M. Hubbard, A. M. Turner and S. P. Monks, Anal. Bioanal. Chem., 2013, 405, 4139.

20 T. M. Allen, T. M. Falconer, M. E. Cisper, A. J. Borgerding and C. W. Wilkerson, Anal. Chem., 2001, 73, 4830.

21 V. Shestivska, V. Kolivoska, J. Kubista, D. Smith and P. Spanel, Rapid Commun. Mass Spectrom., 2020, 34, 1.

22 M. L. Wang, Y. M. Choong, N. W. Su and M. H. Lee, J Food Drug Anal, 2003, 11, 133.

23 M. Bursova, T. Hlozek and R. Cabala, J. Anal. Toxicol., 2015, 39, 741.

24 J. V. D. Broek, S. Abegg, S. E. Prastsinis and A. T. Guntner, Nat. Commun., 2019, 10, 1.

25 D. S. Park, M. S. Won, R. N. Goyal and Y. B. Shim, Sens. Actuators, B, 2012, 174, 45.

26 M. S. F. Santos, E. T. D. Costa, I. G. R. Gutz and C. D. Garcia, Anal. Chem., 2017, 89, 1362.

27 C. Wang, F. Chen, X. W. He, S. Z. Kang, C. C. You and Y. Liu, Analyst, 2001, 126, 1716.

28 V. Kumar, A. Kumar, U. Diwan, M. K. Singh and K. K. Upadhyay, Org. Biomol. Chem., 2015, 13, 8822.

29 Z. Wu, X. Fu and Y. Wang, Sens. Actuators, B, 2017, 245, 406. 30 M. Zhao, Y. Yue, C. Liu, P. Hui, S. He, L. Zhao and X. Zheng, Chem. Commun., 2018, 54, 8339.

31 L. Zhang, H. Qi, Y. Wang, L. Yang, P. Yu and L. Mao, Anal. Chem., 2014, 86, 7280.

32 D. M. Chen, C. X. Sun, Y. Peng, N. N. Zhang, H. H. Si, C. S. Liu and M. Du, Sens. Actuators B, 2018, 265, 104.

33 M. Latha, R. A. Devi, N. K. R. Bogireddy, S. E. S. Rios, W. L. Mochan, J. C. Uribe and V. Agarwal, RSC Adv., 2020, 10, 22522.

34 R. H. Wiley and P. E. Hexner, Org. Synth., 1951, 31, 43.

35 R. R. Gagne, C. L. Spiro, T. J. Smith, C. A. Hamann, W. R. Thies and A. K. Schiemke, J. Am. Chem. Soc., 1981, 103, 4073.

36 International Conference on Harmonization (ICH) of Technical Requirements for Registration of Pharmaceuticals for Human Use, Topic Q2 (R1): Validation of Analytical Procedures: Text and Methodology, 2005, http://www.ich.org. 
37 J. V. Morris, M. A. Mahaney and J. R. Huber, J. Phys. Chem., 1976, 80, 969.

38 M. J. Frisch, et al., Gaussian 09 Rev. A.1, Gaussian Inc., Wallingford CT, 2009.

39 S. Roy, S. Das, R. Majumder, A. Ray and P. P. Parui, RSC Adv., 2020, 10, 23245.

40 J.-J. Delpuech, M. R. Khaddar, A. A. Peguy and P. R. Rubini, J. Am. Chem. Soc., 1975, 97(12), 3373.
41 E. Furia, A. Beneduci, N. Russo and T. Marino, New J. Chem., 2018, 42, 11006.

42 L. Malacaria, G. A. Corrente, A. Beneduci, E. Furia, T. Marino and G. Mazzone, Molecules, 2021, 26, 2603.

43 Guide to Local Production: WHO-recommended handrub formulations (PDF), World Health Organization, WHO/IER/ PSP/2010.5, WHO April, 2010. 